\title{
Simple Insulin Dose Adjustment Using 3-3-1 Algorithm in Japanese Patients with Type 2 Diabetes: Start Kanazawa Study (Self-Titration Aggressive Algorithm with Glargine Trial)
}

\author{
Kenji D. Furukawa, Naoto Yamaaki, Aya Fujimoto, Kiminori Ohyama, Hiroaki Muramoto \\ Department of Internal Medicine, Japan Community Health care Organization (JCHO) Kanazawa Hospital, \\ Kanazawa, Japan \\ Email: kenjif-knz@umin.ac.jp
}

Received 28 July 2016; accepted 14 August 2016; published 17 August 2016

Copyright (C) 2016 by authors and Scientific Research Publishing Inc.

This work is licensed under the Creative Commons Attribution International License (CC BY). http://creativecommons.org/licenses/by/4.0/

cC) (i) Open Access

\begin{abstract}
We implemented a 3-3-1 algorithm in order to provide safe and simple self-titration in patients who newly initiated BOT as well as who were already on BOT and evaluated its utility in clinical setting. A total of 46 patients, 21 patients in the newly-initiated group and 25 patients in the existing BOT group performed dose adjustment using 3-3-1 algorithm. HbA1c was significantly improved 4 weeks after the initiation from $8.5 \% \pm 1.2 \%$ at baseline to $7.3 \% \pm 0.7 \%$ at the final evaluation $(p<0.01$, vs. Baseline). The average daily insulin units increased throughout the study period from $10.1 \pm 6.7$ at baseline to $14.6 \pm 8.9$ units at the final evaluation. Weight didn't significantly change throughout the study $(p=0.12)$. The incidents of hypoglycemia were $0.8 /$ month during the insulin dose selfadjustment period and 0.4/month during the follow-up period. The 3-3-1 algorithm using insulin glargine provided a safe and simple dose adjustment and demonstrated its utility in patients who were newly introduced to insulin treatment as well as who were already on BOT.
\end{abstract}

\section{Keywords}

Glargine, Self-Titration, BOT, T2DM, Insulin, 3-3-1 Algorithm

\section{Introduction}

The goal of diabetes treatment is to maintain the comparable glycemic control and QOL with healthy subjects.

How to cite this paper: Furukawa, K.D., Yamaaki, N., Fujimoto, A., Ohyama, K. and Muramoto, H. (2016) Simple Insulin Dose Adjustment Using 3-3-1 Algorithm in Japanese Patients with Type 2 Diabetes: Start Kanazawa Study (Self-Titration Aggressive Algorithm with Glargine Trial). Journal of Diabetes Mellitus, 6, 197-203. http://dx.doi.org/10.4236/jdm.2016.63022 
Especially in the treatment of type 2 diabetes, it is important to maintain good glucose levels while avoiding hypoglycemia, as well as to manage blood pressure and lipids, in order to prevent progression of complications [1].

It is also critical patients are willing to accept diabetes treatment. The study by Ishii, et al. has suggested that attaining good glycemic control has helped improve patients QOL and increasing patient motivation for the treatment has contributed improvement of adherence to insulin treatment [2]. Thus, in order to continue diabetes treatment, it is considered important that healthcare professionals provide safe and effective medical treatments; patients who are actually given these treatments proactively accept them with positive attitudes.

As one of the most recommended algorithms in medical treatment for type 2 diabetes, basal-supported oral therapy (BOT) which starts with basal insulin is recommended in insulin treatment for the type 2 diabetes from a perspective of avoiding hypoglycemia in patients who are insufficiently controlled with oral hypoglycemic agents such as metformin, according to a position statement of the ADA (American Diabetes Association) and EASD (European Association for the Study of Diabetes) [3].

In recent years, BOT with long-acting soluble insulin analogs has been widely used in Japan. Many studies have already reported BOT using insulin glargine. Our group as well has reported favorable results from the study which examined glargine dose optimization using the ALOHA Dose Calculator for the purpose of safe and adequate dose adjustment in patients with type 2 diabetes who just started insulin treatment or had been treated with insulin but had difficulty to perform SMBG due to issues such as understanding [4].

There have been several studies which have examined dose optimization of insulin. Davies, et al. compared the efficacy and safety between two treatment groups; one with self-administered titration using simple algorithm, another with physician-managed titration and found that the patient group who performed self-administered titration significantly improved HbA1c and increased insulin dose compared with the control group [5].

In addition, the Yki-Jarvinen, et al. study suggested that glycemic control was improved without increasing risk of hypoglycemia by self-administered titration of insulin dose in dose-adjusting period to the equivalent level achieved by physician-managed titration [6].

As mentioned above, there have been studies overseas which investigated insulin self-titration, where patients adjust insulin dose by themselves using simple algorithm. However in Japan, we have not reached a certain consensus yet to establish any algorithm.

Hosaka, et al. reported a study which examined 3-3-1 algorithm, created based on self-titration algorithm by Yki-Jarvinen, et al. In the 3-3-1 algorithm, patients add 1 unit of basal insulin when morning fasting SMBG values exceed 3 digits in the most recent 3 consecutive days [7]. Additional dosage unit of basal insulin in this algorithm is set to be half of the dosage in the overseas algorithm in considering safety issues such as hypoglycemia.

In this study, we implemented 3-3-1 algorithm in patients who newly initiated BOT as well as in patients already on BOT in order to provide a safe and easy-to-use self-titration and examined its utility in clinical practice.

\section{Study Participants and Methods}

\subsection{Study Participants}

A total of 46 patients with type 2 diabetes who were outpatients or inpatients treated in our hospital between July 2014 and July 2015 were enrolled. They were on treatment with diet and exercise as well as medical treatment (oral hypoglycemic agents (OHA) or OHA + basal insulin) but their blood glucose was inadequately controlled. Baseline patient characteristics are shown in Table 1. Twenty-one patients were included in the newly-initiated group: newly introduced insulin treatment with glargine based BOT. The other 25 patients were included in the existing BOT group, already on BOT. The mean age was $60.3 \pm 10.9$ years and the mean duration of diabetes was $8.4 \pm 7.8$ years. The baseline HbA1c and BMI were $8.5 \% \pm 1.2 \%$ and $26.6 \pm 4.1 \mathrm{~kg} / \mathrm{m}^{2}$, respectively.

\subsection{Methods}

Both the newly-initiated group and the existing BOT group started BOT with once daily of insulin glargine at the first office visit of the study. To be included in the study, patients had to be aged more than 20 years, treated OAD therapy and started treatment with insulin glargine as BOT. In addition, patients have HbA1c levels were more than $8.0 \%$ in the 4 weeks before study period. During the first 8 weeks of the study (week $0-8$ ), an insulin 
Table 1. Baseline characteristics of the patients.

$\begin{array}{cc}\text { Subjects } & 46 \\ \text { Newly inslinization } & 21 \\ \text { Already used insulin } & 25 \\ \text { Sex } & \text { Male 36, Female } \\ \text { Age (old) } & 60.3 \pm 10.9 \\ \text { Duration of Diabetes (years) } & 8.4 \pm 7.8 \\ \text { HbA1c (\%) (NGSP) } & 8.5 \pm 1.2 \\ \text { Body weight (kg) } & 73.3 \pm 13.0 \\ \text { BMI (kg/m }{ }^{2} \text { ) } & 26.6 \pm 4.1 \\ \text { Initial daily dose of Glargine (Unit) } & 10.1 \pm 6.7 \\ & \text { Mean } \pm \mathrm{SD}\end{array}$

dose self-adjustment period, the starting dose was 4 to 6 units for the newly-initiated group and equivalent dose to the daily average amount over the previous basal insulin treatment for existing BOT group. According to 3-3-1 algorithm, both groups were asked to increase the dose of insulin glargine by 1 unit when fasting SMBG exceeded 3 digits $(100 \mathrm{mg} / \mathrm{dL})$ in the most recent 3 consecutive days. The target fasting glucose was $100 \mathrm{mg} / \mathrm{dL}$. At the second office visit 2 weeks after the initiation, the participants were asked if they understand the algorithm. During week 8 through 24, which was follow-up period, insulin and OHA dose was adjusted according to doctors' decision. If hypoglycemia events defined as SMBG less than $70 \mathrm{mg} / \mathrm{dL}$ and symptomatic hypoglycemia such as cold sweat occurred, insulin glargine dose was decreased accordingly based on the participants or doctors' decision. This study design was reviewed and approved by the medical ethics committee of Japan Community Healthcare Organization, Kanazawa Hospital in July, 2014.

\subsection{Endpoints}

The primary endpoint was change in HbA1c from baseline, assessed in average \pm S.E. The secondary endpoints were change in daily dose of insulin glargine, hypoglycemic incident rate, and weight change. They were evaluated for 24 weeks and the final evaluation was made in January, 2016.

Paired-t test was used for hypothesis testing. Statistical testing was performed at a two-sided significance level of 0.05 .

Treatment satisfaction was also assessed by asking all of participants to fill questionnaire at the beginning and the end of the study.

\section{Results}

\subsection{Study Results}

Changes in HbA1c and average daily insulin units are shown in Figure 1. HbA1c was significantly improved 4 weeks after the initiation from $8.5 \% \pm 1.2 \%$ at baseline to $7.3 \% \pm 0.7 \%$ at the final evaluation $(\mathrm{p}<0.01$, vs. baseline). The average daily insulin units increased throughout the study period from $10.1 \pm 6.7$ at baseline, achieving $16.2 \pm 7.7$ units at week 8 during insulin dose self-adjustment period while declining to $14.6 \pm 8.9$ units at the final evaluation ( $\mathrm{p}<0.01$, vs. Baseline).

Secondly, weight change and hypoglycemia incident rates are shown in Figure 2. Weight didn't significantly change throughout the study, $73.3 \pm 13.0 \mathrm{~kg}$ at baseline and $73.8 \pm 13.0 \mathrm{~kg}$ at the final evaluation.

The incidents of hypoglycemia were 0.8 /month during the insulin dose self-adjustment period of week 0 - 8 and 0.4/month during the follow-up period of week 8 - 24 . 
(\%)

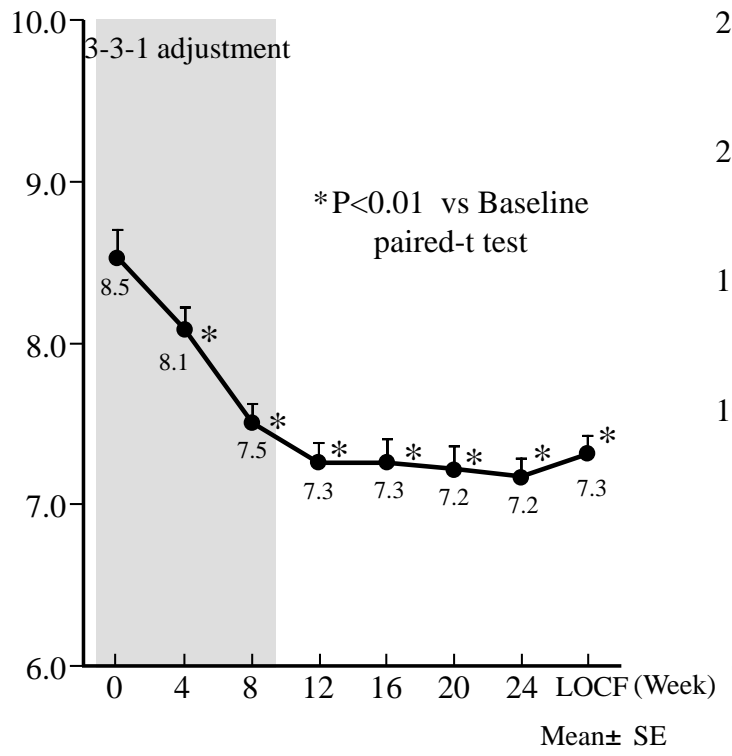

(a)
(Unit)

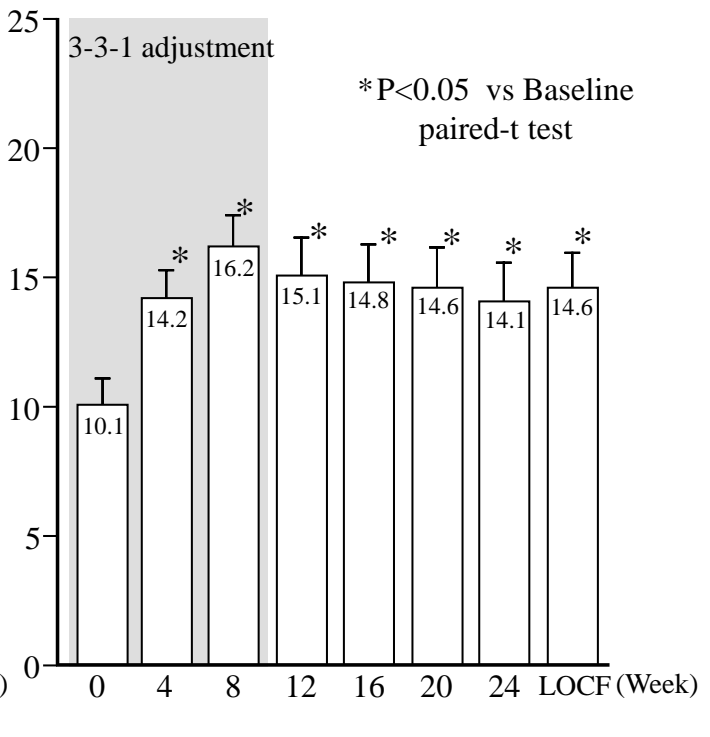

(b)

Figure 1. Changes of HbA1c (a) and Total daily glargine dose (b).

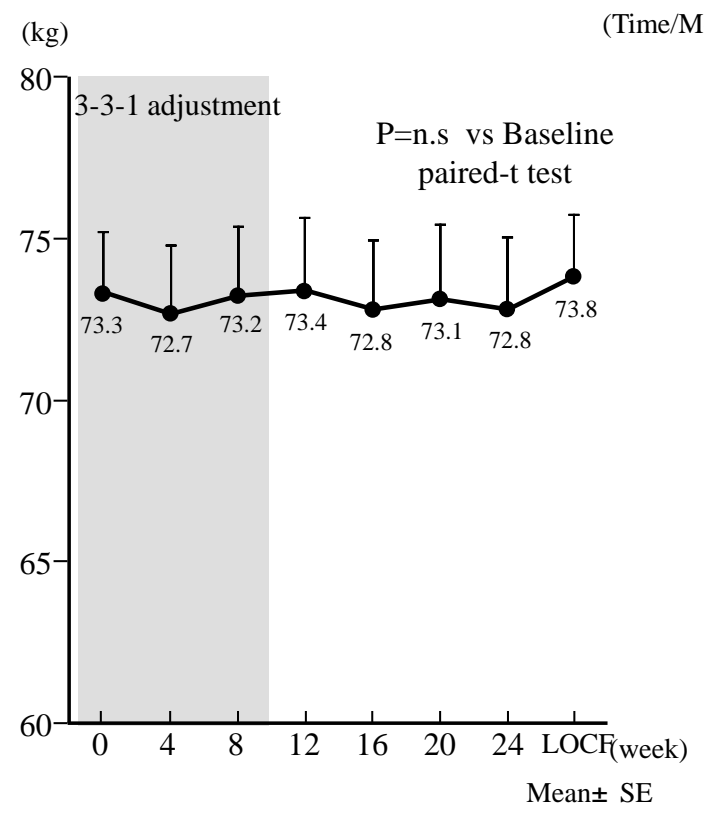

(a)

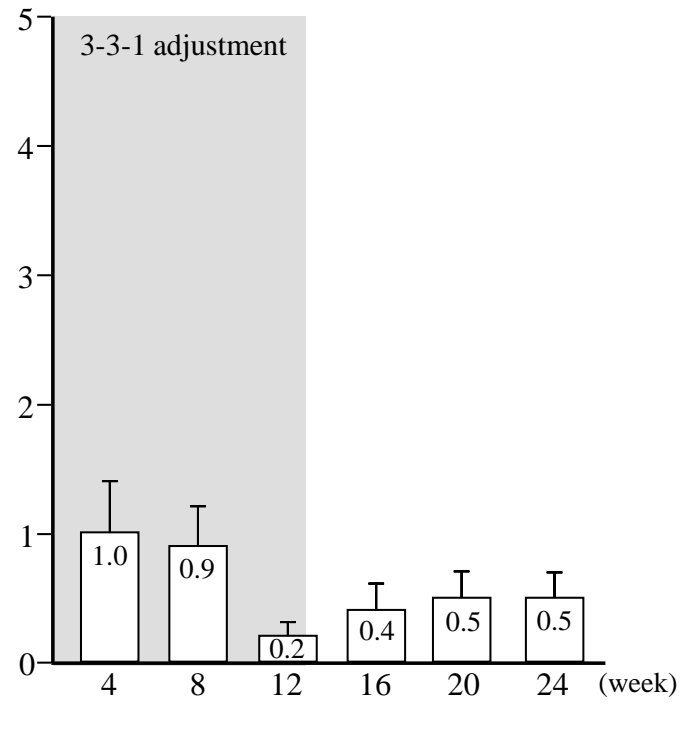

(b)

Figure 2. Changes of body weight (a) and Hypoglycemia (b).

The results of questionnaire for treatment satisfaction are shown in Figure 3. "Glucose level before and after insulin initiation" was improved from $1.8 \pm 0.2$ before the study to $4.2 \pm 0.1$ at the final evaluation, assessed on a scale of 1 to 5 . "Feeling before and after insulin initiation" was also improved from $1.9 \pm 0.1$ before the study to $3.2 \pm 0.2$ at the final evaluation.

Of the positive answers for the feeling to insulin treatment, "I became positive to diabetes treatment" was the highest, 34.0\% responded YES; and "I felt like treating by myself" was the second highest positive statement with $24 \%$ in agreement. As for negative comments, "I was anxious" was top rated, which was cited by $18 \%$. No one claimed "I became worse". 


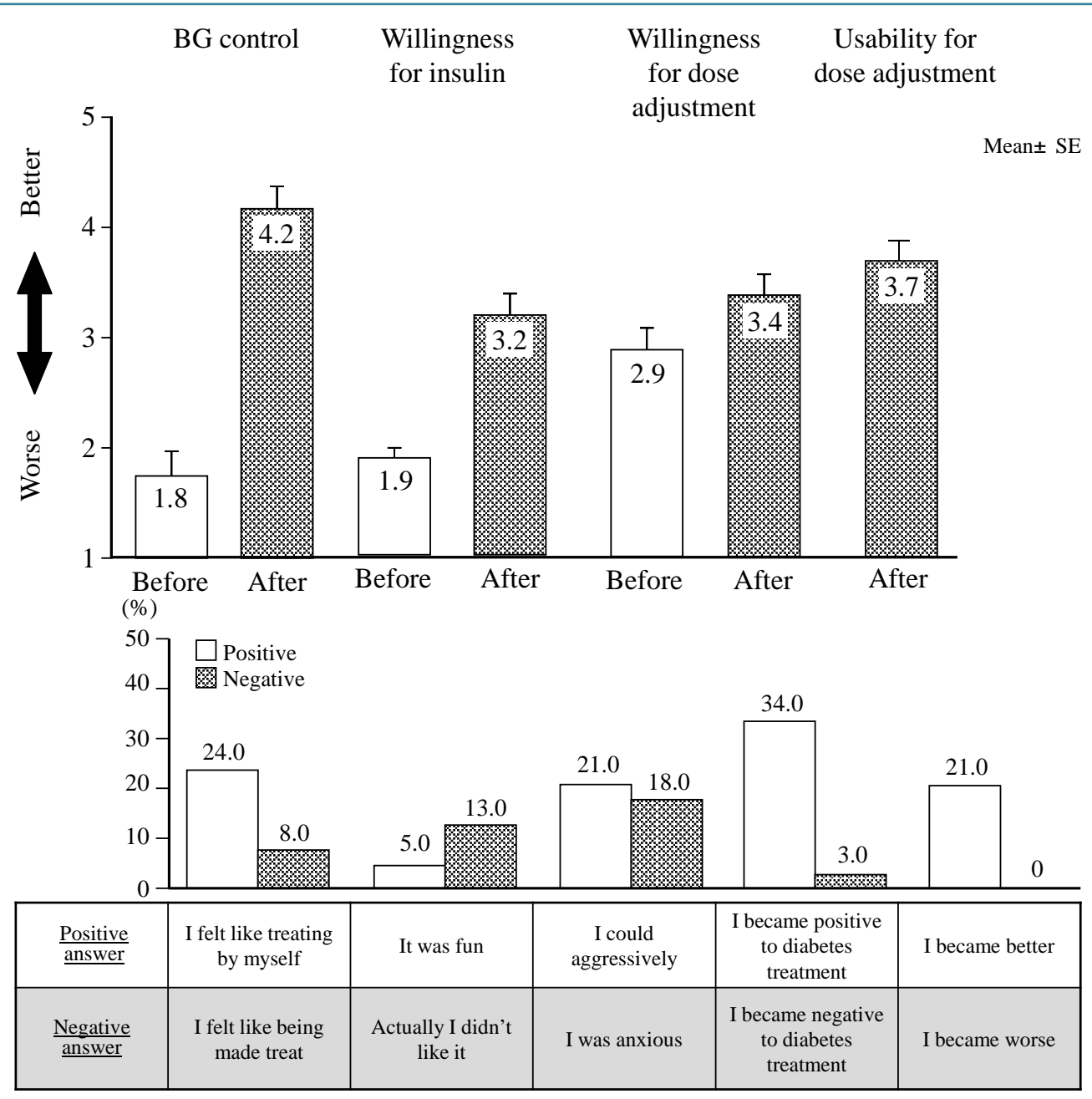

Figure 3. The results of questionnaire for treatment satisfaction.

\subsection{Analysis by Patient Group}

\subsubsection{Newly-Initiated Group}

In newly-initiated group including 21 patients, HbA1c was significantly improved 4 weeks after the initiation from $9.3 \% \pm 1.3 \%$ at baseline to $7.0 \% \pm 0.8 \%$ at the final evaluation $(\mathrm{p}<0.01$, vs. baseline. The average daily insulin units increased throughout the study period from $5.9 \pm 2.5$ at baseline, achieving $13.5 \pm 5.8$ units at week 8 during insulin dose self-adjustment period while declining to $10.0 \pm 7.5$ units at the final evaluation $(\mathrm{p}<0.05$, vs. baseline).

\subsubsection{Existing BOT Group}

In nineteen patients of existing BOT group, $\mathrm{HbA1c}$ was significantly improved 4 weeks after the study began from $7.9 \% \pm 0.6 \%$ at baseline to $7.6 \% \pm 0.6 \%$ at the final evaluation ( $<<0.01$, vs. baseline). The average daily insulin units increased throughout the study period from $13.6 \pm 7.1$ at baseline, achieving $19.0 \pm 8.5$ units at week 8 during insulin dose self-adjustment period while declining to $18.5 \pm 8.3$ units at the final evaluation ( $\mathrm{p}<$ 0.05 , vs. baseline). The incidence of hypoglycemia at that time was $0.6 /$ month.

\section{Discussion}

Basal insulin based BOT is recommended as the first step of insulin introduction overseas since it is considered as a safe insulin regimen with less hypoglycemia risk, as well as a simple treatment compared with multiple daily insulin injections because it involves only once daily insulin injection [3]. 
There is a study which suggested that it improved endogenous insulin secretory function by rectifying fasting glucose to near normal level [8].

As represented by ALOHA study, the utility of BOT in clinical setting has been reported in many cases in Japan [9]. While BOT is considered as safe and simple treatment, issues still remain in maintaining good glycemic control.

In sub-analysis from ALOHA study, for example, 1353 patients which is $42.5 \%$ of total study population did not achieve HbA1c less than 7.0\% while their average daily insulin units was comparably low with less than 8.5 units at week 24, the end of the study [10]. This implies the possibility that insulin was not sufficiently replenished. The most possible background for such issues could be that doctors were reluctant for frequent titration from concerns about hypoglycemia. It might be also related the fact that simple and easy-to-use algorithm of insulin dose has not reached consensus and that dose adjustment based on fasting glucose was not easy because performing SMBG was difficult due to the issues of patients willingness and understanding.

In the current study, in order to solve such challenges, we introduced 3-3-1 algorithm which is simple and easy to understand for patients and successfully implemented the self-titration based on fasting glucose by themselves. As a result, glycemic control was improved without hypoglycemia and treatment satisfaction reached high level in most participants. Of particular note is the findings that 34\% responded "I became positive to diabetes treatment" and $24 \%$ answered "I felt like treating by myself" in the patient questionnaire. This suggested that performing self-titration is effective for improving patient motivation to the treatment and empowering them to actively participate the treatment.

The reports for the utility of self-titration have been found in some overseas studies but limited in Japan [11]. In the current study, it is suggested that the patient-led insulin dose adjustment using insulin glargine with outpatient 3-3-1 algorithm for Japanese patients with type 2 diabetes is an effective way to achieve safe and optimal glycemic control.

For this study, we used insulin glargine $100 \mathrm{U} / \mathrm{mL}$ (Bland name: Lantus) for 3-3-1 algorithm.

As of July 2016, insulin glargine $300 \mathrm{U} / \mathrm{mL}$ (Bland name: Lantus XR), which contains 3 times as much active ingredients in $1 \mathrm{~mL}$ as insulin glargine $100 \mathrm{U} / \mathrm{mL}$, is available in Japan. Lantus XR provides flatter and more than 24 hours of insulin activity profile by the mechanism of more gradual dissolution than Lantus [12] [13]. In the phase III clinical trial in Japan, Lantus XR demonstrated clinical benefits such as less risk of nocturnal and 24-hour hypoglycemia and less weight change than Lantus [14] [15]. In addition, it can be given at any time of the day when taken once daily at the same time each day, possibly letting patients adjust dose timing to their lifestyle. It would be interesting to see clinical outcomes from the self-titration with 3-3-1 algorithm implemented in our study which uses this newcomer Lantus XR. Such studies are anticipated in the future.

\section{Conclusions}

The 3-3-1 algorithm using insulin glargine provided safe and simple dose adjustment and demonstrated its utility in patients who were newly introduced insulin treatment as well as who were already on BOT.

The sample size was small in this study and the analysis with more participants would be warranted.

\section{References}

[1] Inzucchi, S.E., et al. (2012) Management of Hyperglycemia in Type 2 Diabetes: A Patient-Centered Approach. Position Statement of the American Diabetes Association (ADA) and the European Association for the Study of Diabetes (EASD). Diabetes Care, 35, 1364-1379. http://dx.doi.org/10.2337/dc12-0413

[2] Ishii, H., et al. (2008) Improvement of Glycemic Control and Quality-of-Life by Insulin Lispro Therapy: Assessing Benefits by ITR-QOL Questionnaires. Diabetes Research and Clinical Practice, 81, 169-178. http://dx.doi.org/10.1016/j.diabres.2008.03.020

[3] Inzucchi, S.E., et al. (2015) A Patient-Centered Approach. Update to a Position Statement of the American Diabetes Association and the European Association for the Study of Diabetes. Diabetes Care, 38, 140-149. http://dx.doi.org/10.2337/dc14-2441

[4] Furukawa, K., et al. (2014) Glargine Dose Optimization using ALOHA Dose Calculator with T2DM in Japan (GOLDJ Study). Journal of New Remedies \& Clinics, 63, 771-777.

[5] Davies, M., et al. (2005) Improvement of Glycemic Control in Subjects with Poorly Controlled Type 2 Diabetes: Comparison of Two Treatment Algorithms Using Insulin Glargine. Diabetes Care, 28, 1282-1288. http://dx.doi.org/10.2337/diacare.28.6.1282 
[6] Yki-Järvinen, H., et al. (2007) Initiate Insulin by Aggressive Titration and Education (INITIATE): A Randomized Study to Compare Initiation of Insulin Combination Therapy in Type 2 Diabetic Patients Individually and in Groups. Diabetes Care, 30, 1364-1369. http://dx.doi.org/10.2337/dc06-1357

[7] Hosaka, T., et al. (2014) Current Issue and Future Strategy of BOT (Basal-supported Oral Therapy). Journal of New Remedies \& Clinics, 63, 837-843.

[8] Meier, J.J., et al. (2013) Hyperglycaemia Is Associated with Impaired Pulsatile Insulin Secretion: Effect of Basal Insulin Therapy. Diabetes, Obesity and Metabolism, 15, 258-263. http://dx.doi.org/10.1111/dom.12022

[9] Otani, T., et al. (2011) The Safety and Usefulness of BOT (Basal Supported Oral Therapy) Using Insulin (ALOHA Study) — Based on the Result of the Lantus ${ }^{\circledR}$ Drug Use Survey "Investigation of the Concomitant Use of Oral Hypoglycemic Drugs (Type 2 Diabetes). Journal of New Remedies and Clinics, 60, 458-475.

[10] Odawara, M., et al. (2012) Dosing of Insulin Glargine to Achieve the Treatment Target in Japanese Type 2 Diabetes on a Basal Supported Oral Therapy Regimen in Real Life: ALOHA Study Subanalysis. Diabetes Technology \& Therapeutics, 14, 635-643. http://dx.doi.org/10.1089/dia.2011.0220

[11] Bosco, D., et al. (2015) An Educational Program for Insulin Self-Adjustment Associated with Structured Self-Monitoring of Blood Glucose Significantly Improves Glycemic Control in Patients with Type 2 Diabetes Mellitus after 12 Weeks: A Randomized, Controlled Pilot Study. Diabetology \& Metabolic Syndrome, 7, 2. http://dx.doi.org/10.1186/1758-5996-7-2

[12] Steinstraesser, A., et al. (2014) Investigational New Insulin Glargine $300 \mathrm{U} / \mathrm{ml}$ Has the Same Metabolism as Insulin Glargine 100 U/ml. Diabetes, Obesity and Metabolism, 16, 873-876. http://dx.doi.org/10.1111/dom.12283

[13] Becker, R.H., et al. (2015) New Insulin Glargine 300 Units/mL Provides a More Even Activity Profile and Prolonged Glycemic Control at Steady State Compared with Insulin Glargine 100 Units/mL. Diabetes Care, 38, 637-643.

[14] Matsuhisa, M., et al. (2016) New Insulin Glargine 300 U/ml versus Glargine 100 U/ml in Japanese Adults with Type 1 Diabetes Using Basal and Mealtime Insulin: Glucose Control and Hypoglycaemia in a Randomized Controlled Trial (EDITION JP 1). Diabetes, Obesity and Metabolism, 18, 375-383. http://dx.doi.org/10.1111/dom.12619

[15] Terauchi, Y., et al. (2016) New Insulin Glargine 300 U/ml versus Glargine 100 U/ml in Japanese People with Type 2 Diabetes Using Basal Insulin and Oral Antihyperglycaemic Drugs: Glucose Control and Hypoglycaemia in a Randomized Controlled Trial (EDITION JP 2). Diabetes, Obesity and Metabolism, 18, 366-374.

http://dx.doi.org/10.1111/dom.12618

\section{Submit or recommend next manuscript to SCIRP and we will provide best service for you:}

Accepting pre-submission inquiries through Email, Facebook, LinkedIn, Twitter, etc.

A wide selection of journals (inclusive of 9 subjects, more than 200 journals)

Providing 24-hour high-quality service

User-friendly online submission system

Fair and swift peer-review system

Efficient typesetting and proofreading procedure

Display of the result of downloads and visits, as well as the number of cited articles

Maximum dissemination of your research work

Submit your manuscript at: http://papersubmission.scirp.org/ 